\title{
The Effect of Verapamil on TXNIP Gene Expression, GLP1R mRNA, FBS, HbA1c, and Lipid Profile in T2DM Patients Receiving Metformin and Sitagliptin
}

\author{
Alireza Malayeri · Mehrnoosh Zakerkish · Farrokh Ramesh • \\ Hamid Galehdari · Ali Asghar Hemmati · Kambiz A. Angali
}

Received: July 15, 2021 / Accepted: August 16, 2021 / Published online: September 4, 2021

(C) The Author(s) 2021

\section{ABSTRACT}

Introduction: Type 2 diabetes mellitus (T2DM) is the most common type of diabetes. A decrease in the number of pancreatic beta cells is a pathological sign of diabetes, and to date there is no drug treatment that targets damage to these cells. Pancreatic beta cells have a weak antioxidant system and are highly sensitive to oxidative stress reactions that occur within cells. Thioredoxin interacting protein (TXNIP) inhibits thioredoxin, which is part of the

\section{A. Malayeri · F. Ramesh}

Department of Pharmacology, School of Pharmacy, Ahvaz Jundishapur University of Medical Sciences, Ahvaz, Iran

\section{Zakerkish ( $\square)$}

Department of Internal Medicine, Diabetes Research Centre, Health Research Institute, Ahvaz

Jundishapur University of Medical Sciences, Ahvaz, Iran

e-mail: zakerkish-m@ajums.ac.ir

\section{H. Galehdari}

Department of Genetics, Faculty of Sciences, Shahid Chamran University of Ahvaz, Ahvaz, Iran

\section{A. A. Hemmati}

Medicinal Plant Research Center, School of Pharmacy, Ahvaz Jundishapur University of Medical Sciences, Ahvaz, Iran

\section{K. A. Angali}

Department of Biostatistics and Epidemiology, School of Health, Ahvaz Jundishapur University of Medical Sciences, Ahvaz, Iran intracellular antioxidant system, thereby accelerating oxidative stress and apoptosis of pancreatic beta cells. Verapamil is a nondihydropyridine calcium channel blocker. The efficacy of this drug to improve beta cell survival and glucose homeostasis by inhibiting TXNIP expression has been demonstrated in in vitro studies. Although several retrospective studies have shown a lower incidence of T2DM with verapamil treatment, no prospective intervention studies have determined the efficacy of this drug in patients with T2DM.

Methods: The aim of this randomized, doubleblind, placebo-controlled study was to evaluate the efficacy and safety of oral verapamil administration in T2DM patients. In this 90-day study, the effects of verapamil on fasting blood sugar (FBS), hemoglobin A1C (HbA1c), and the lipid profile were evaluated and compared with those of the placebo.

Results: There was a significant decrease in HbA1c (about $0.5 \%$ ) in the verapamil group at the end of the intervention period. The effects of verapamil on TXNIP gene expression and glucagon-like peptide-1 receptor (GLP1R) mRNA were compared with those of the placebo (at baseline, after 15 and 30 days, and at the end of the study). During the first month of the study, decreased TXNIP gene expression and increased GLP1R mRNA were associated with the administration of verapamil when compared with the placebo, although the differences were not significant. 
Conclusion: Verapamil can lead to better control of T2DM by reducing TXNIP gene expression and increasing beta cell survival and, possibly, by other mechanisms.

Clinical Trial Registration: IRCT registration no.: IRCT20180417039339N1 (https://www. IRCT.ir).

Keywords: Type 2 diabetes; Randomized controlled trials; Verapamil; TXNIP

\section{Key Summary Points}

Why carried out this study?

The aim of this study was to prevent worsening of type 2 diabetes mellitus through a new treatment path that involves improving pancreatic beta cell survival by reducing thioredoxin interacting protein (TXNIP) gene expression.

\section{What was learned from this study?}

Patients with T2DM treated with verapamil, which has been shown to inhibit TXNIP expression, showed a significant decrease in hemoglobin A1C compared to the placebo group.

TXNIP gene expression was decreased in the verapamil group compared to the placebo group, although the difference was not significant.

The results show that verapamil can lead to better control of T2DM by reducing TXNIP gene expression and increasing beta cell survival; more improvement may be achieved by further reducing TXNIP gene expression through increasing the dose of verapamil.

\section{INTRODUCTION}

Type 2 diabetes mellitus (T2DM) refers to a set of metabolic disorders characterized by hyperglycemia and caused by insulin resistance, insufficient insulin secretion, reduced or lost incretin effect, and excessive or inappropriate glucagon secretion $[1,2]$. Pancreatic beta cells have a weak antioxidant system and are highly sensitive to oxidative stress reactions that occur within the cell [3]. Thioredoxin interacting protein (TXNIP) inhibits thioredoxin, which results in reduced antioxidant capacity of cells and induces oxidative stress and apoptosis in pancreatic beta cells, thereby reducing the insulin production capacity of beta cells $[3,4]$. Thioredoxin is a thiol oxidoreductase and is part of the extensive intracellular antioxidant system in mammals that protects cells against oxidative stress [5]. The thioredoxin system prevents the oxidation of intracellular proteins by oxidating the two cysteine components of thioredoxin $[6,7]$ and is also involved in several other intracellular processes, including proliferation and apoptosis [6-9]. TXNIP is a 46-kDa protein that contains 391 amino acids; it is part of the family of alpha arrestins [10] and performs multiple activities and is involved in cell homeostasis [11]. This protein is present in the cytoplasm [12-14] but is also transferred into the mitochondria and nuclei [15]. The coding sequence of TXNIP was identified in the mid1990s [16], and its association with pancreatic beta cells was demonstrated 8 years later [17]. In human cell culture and animal models, the TXNIP gene is induced by glucose, and its expression is increased under hyperglycemic conditions $[4,14,18]$. TXNIP can also stimulate its own expression [19], which means that the induction of TXNIP production by glucose is enhanced by TXNIP itself. On the other hand, it has been shown that insulin reduces TXNIP expression in beta cells, muscles, and adipose tissue $[18,20]$. TXNIP binds reversibly to thioredoxin-1 [21] and is associated with mitochondrial thioredoxin- 2 and the induction of apoptosis [15]. Specifically, TXNIP interferes with the denitrosylation of proteins [22], and it can also exert some of its effects independently of thioredoxin [23, 24]. TXNIP inhibits the expression of target genes, including vital transcription factors for insulin production, by entering the cell nucleus and expressing several types of microRNAs [25]. TXNIP has recently 
been shown to induce the expression of a specific microRNA, microRNA-204 (or miR204), by inhibiting the activity of a transcription factor involved in the regulation of this microRNA [25-27]. By binding to the mRNA responsible for the synthesis of the glucagonlike peptide-1 receptor (GLP1R), thus inhibiting its function, this microRNA reduces the production of this receptor in pancreatic beta cells and possibly reduces the effect of incretin [28].

Verapamil is a non-dihydropyridine calcium channel blocker used to treat hypertension, supraventricular arrhythmias such as atrial fibrillation, and angina pectoris [31] that was introduced onto the pharmaceutical market in the early 1960s [29]. The pharmacokinetic parameters of this drug depend heavily on the drug formulation. The immediate-release form of this drug reaches its peak plasma concentration within $1-2 \mathrm{~h}$ after administration, whereas the sustained-release formulation requires 6-11 $\mathrm{h}$ to reach this state. The AUC and maximum (or peak) serum concentration also depend on the specific drug formulation [30-32].

It has recently been shown in cell culture medium and in an animal model that verapamil can improve beta cell survival and glucose homeostasis by reducing TXNIP expression [33]. The effectiveness of verapamil in diabetes has also been demonstrated in several retrospective studies [34-37]. In addition, a prospective study conducted in 2018 showed the efficacy of the drug in patients with type 1 diabetes, which was associated with improved beta cell function [38]. Based on these results, it would appear that verapamil is likely to be associated with better control of diabetes in T2DM patients. The aim of this study, therefore, was to evaluate the effect of verapamil in patients with T2DM by investigating its effect on TXNIP gene expression and GLP1R mRNA. Verapamil is also likely to improve T2DM by inhibiting TXNIP gene expression and increasing the GLP1R level in pancreatic beta cells, among other possible mechanisms.

\section{METHODS}

\section{Study Design and Participants}

The trial was designed as a randomized, doubleblind, placebo-controlled study. A block randomization approach was used to randomize participants at a 1:1 ratio to receive verapamil or placebo. Inclusion criteria were: age between 40 and 67 years; currently treated with oral antihyperglycemic drugs, including metformin and sitagliptin; diagnosis of T2DM at enrollment of at least 5 years; hemoglobin A1C (HbA1c) level $>6.5 \%$. Women of childbearing age who used contraceptives during the study were also eligible to participate. Individuals with the following conditions were excluded: pregnant and lactating women and any patient with uncompensated heart failure, increased body fluid volume or fluid overload, previous heart attack, or evidence of severe heart disease during the 3 months immediately preceding the study, left ventricular dysfunction, grade $2 / 3$ heart block, prolonged PR intervals on the electrocardiogram or the presence of any arrhythmic bradycardia, Wolff-Parkinson-White syndrome or Lown-Ganong-Levine syndrome, hypotension (systolic blood pressure $<90 \mathrm{mmHg}$ ), peripheral or cerebrovascular disease, cancer, epilepsy, cystic fibrosis, sickle cell anemia, concomitant use of drugs that affect blood glucose levels (glucocorticoids, hydrochlorothiazide, antipsychotics), creatinine levels $>1.5 \mathrm{mg} / \mathrm{dl}$ ( $1.4 \mathrm{mg}$ in women), aspartate aminotransferase, alanine aminotransferase and bilirubin levels $>1.5$ upper limits of normal, any injectable contrast agent use during the study, insulin use, and sensitivity to verapamil.

Participants were randomly allocated to receive verapamil $(120 \mathrm{mg}$ ) or placebo for a total of 90 days in addition to their medications for T2DM. Dosage of the drug was selected in the treatment range of verapamil and in accordance with the majority of prescriptions containing this drug in Iran. Participants were carefully monitored for any occurrence of adverse drug reactions until the end of the study. The patients were selected in the Diabetes Clinic of Imam Khomeini Hospital in Ahvaz, Khuzestan, 
Iran, and patients did not pay any fees at any stage of the study; all costs were borne by Ahwaz Jundishapur University of Medical Sciences.

\section{Randomization and Masking}

The placebo for this study was produced by the Faculty of Pharmacy of Ahvaz Jundishapur University of Medical Sciences. The placebo had a similar shape, size and color as verapamil and was in identical packaging. Different lot numbers were assigned to the drug and placebo. During the study, the researchers and participants could not access the codes assigned to the drug and placebo. This information was not released until after the data analysis was completed.

\section{Procedures}

A total of 44 patients were randomly divided into two groups, and either the drug or the placebo was added to each patient's treatment regimen. The baseline characteristics of the two treatment groups were well-balanced, with no significant differences in any of the characteristics. In addition, the average HbA1c value was similar in the verapamil and placebo groups. Laboratory tests, including fasting blood sugar (FBS), HbA1c, and lipid profile tests, were measured at the beginning of the study and after 90 days (end of intervention). Glucose and lipid profiles were measured using a Pars Azmun test kit (Pars Azmun Co., Tehran, Iran), and HbA1c was measured using high-performance liquid chromatography. Genetic tests were performed to determine the frequency of TXNIP gene expression and GLP1R mRNA on blood samples collected before the start of the study, at 15 and 30 days, respectively, into the study, and at the end of the intervention (90 days after first administration of verapamil or placebo).

Peripheral blood samples were collected by venipuncture into sodium citrate tubes, and peripheral blood mononuclear cells (PBMC) were prepared by Ficoll-Hypaque density centrifugation. After PBMC separation, total RNA was isolated using TRIzol reagent. UV-Vis spectrophotometry was used to quantify and assess purity of the RNA at 260/280 nm (NanoDrop $^{\mathrm{TM}}$ One Microvolume UV-Vis spectrophotometer; Thermo Fisher Scientific, Waltham, MA, USA). A 1- $\mu \mathrm{g}$ aliquot of total RNA was reverse-transcribed using a cDNA synthesis kit (YTA, Tehran, Iran) according to the supplier's instructions. Complementary DNA copy (cDNA) was stored at $-20^{\circ} \mathrm{C}$ until required for the PCR. Real-time PCR was performed using SYBR Green (YTA SYBR Green qPCR MasterMix $2 \times$; YTA) on a high-performance LightCycler ${ }^{\circledR}$ 96 Instrument real-time PCR system (Hoffmann-La Roche, Basel, Switzerland). The betaactin (ACTB), TXNIP, and GLP1R genes were quantified, and these values were compared against standard curves for cycle threshold (Ct). Relative amounts of the TXNIP gene and the GLP1R mRNA were normalized to that of the ACTB using the $2^{-\Delta \Delta C t}$ method as reported by Livak and Schmittgen [39].

\section{Statistical Analysis}

The SPSS version 16 software package (SPSS IBM Corp., Armonk, NY, USA) was used to analyze the FBS, HbA1c, and lipid profile (including total triglyceride [TG], low-density lipoprotein [LDL] cholesterol, and high-density lipoprotein [HDL] cholesterol levels) measurements made at the beginning and end (90 days after intervention) of the trial. Statistical summaries were expressed as the mean \pm standard deviation, and the Kolmogorov-Smirnov test was used to check normality before data analysis. Independent samples $t$ tests were used to compare patients' demographic data and general characteristics, as well as results of the FBS, HbA1c, and lipid profile laboratory tests before the study, as well as to compare the effects of verapamil and placebo on laboratory test results at the end of the study. Paired-samples $t$ tests were utilized to compare the effects of verapamil and placebo before and after the study within each group. Non-parametric equivalent methods were used when the data were not normal.

TXNIP gene expression and GLP1R mRNA were measured at baseline (prior to intervention), after 15 and 30 days, and at the end of the 
Table 1 Baseline demographic and general characteristics of participants who completed the study

\begin{tabular}{llll}
\hline Variables & Verapamil group $(\boldsymbol{n}=\mathbf{2 2})$ & Placebo group $(\boldsymbol{n}=\mathbf{2 0})$ & $\boldsymbol{p}$ value \\
\hline Age (years) & $52.9 \pm 7.3$ & $52.2 \pm 8.4$ & 0.77 \\
Gender (male/female) & $11 / 11$ & $7 / 13$ & 0.32 \\
Body weight $(\mathrm{kg})$ & $77.7 \pm 12.2$ & $76.5 \pm 14.8$ & 0.76 \\
Body height (m) & $1.68 \pm 0.86$ & $1.65 \pm 0.97$ & 0.19 \\
BMI $\left(\mathrm{kg} / \mathrm{m}^{2}\right)$ & $27.4 \pm 5.3$ & $28.1 \pm 5$ & 0.66 \\
Sulfonylurea (-/+) & $13 / 9$ & $12 / 8$ & 0.21 \\
SGLT2 inhibitor (-/+) & $17 / 5$ & $18 / 2$ & 0.26 \\
Thiazolidinedione (-/+) & $19 / 3$ & $18 / 2$ & 0.71 \\
Meglitinide (-/+) & $19 / 3$ & $19 / 1$ & 0.34 \\
Statin $(-/+)$ & $6 / 16$ & $7 / 13$ & 0.58 \\
Fibrate (-/+) & $21 / 1$ & $19 / 1$ & 0.94 \\
Hypertension (-/+) & $17 / 5$ & $17 / 3$ & 0.54 \\
\hline Data & &
\end{tabular}

Data are shown as the mean \pm standard deviation $(\mathrm{SD})$ or as number of patients among those who were tested $B M I$ Body mass index, SGLT2 sodium-glucose co-transporter 2

study. Independent samples $t$ tests were carried out to compare the genetic data of the two groups at each of the studied time-points (i.e., on days 15, 30, and 90). The Mann-Whitney statistical method was used when the data were not normal. The repeated measures statistical method was used to compare genetic data during the study and within each group.

In this study, a 95\% confidence interval and average SD of the two groups of 100 were considered. Also, the intention-to-treat approach was used to modify the data because five participants did not complete the trial.

\section{Compliance with Ethical Guidelines}

The trial protocol was approved by the Ahvaz Jundishapur University of Medical Sciences and complied with all ethical regulations (IR.AJUMS.REC.1394.284). All patients provided written consent. This study was officially registered on the Iranian Registry of Clinical Trials website (IRCT20180417039339N1, 07/08/ 2018). The study was performed in accordance with the Declaration of Helsinki 1964 and its later amendments.

\section{RESULTS}

\section{Patient Demographic Characteristics and Laboratory Test Data at Baseline}

A total of 44 patients with T2DM aged between 40 and 67 years participated in this study. These patients were randomly divided into two groups: an intervention group which received oral verapamil, and a group which received oral placebo. Among those patients receiving verapamil, nine were currently taking sulfonylurea, five were taking a sodium/glucose cotransporter 2 (SGLT2) inhibitor (empagliflozin), three were taking a thiazolidinedione (pioglitazone), and three were taking a meglitinide (repaglinide). Among patients receiving placebo, eight were taking a sulfonylurea, two were taking SGLT2 inhibitors, two were taking a thiazolidinedione and one was taking a meglitinide. The antihyperlipidemic drugs used by patients in both groups are listed in Table 1 . There was no 


\section{CONSORT}

TRANSPARENT REPORTING of TRIALS

\section{CONSORT 2010 Flow Diagram}

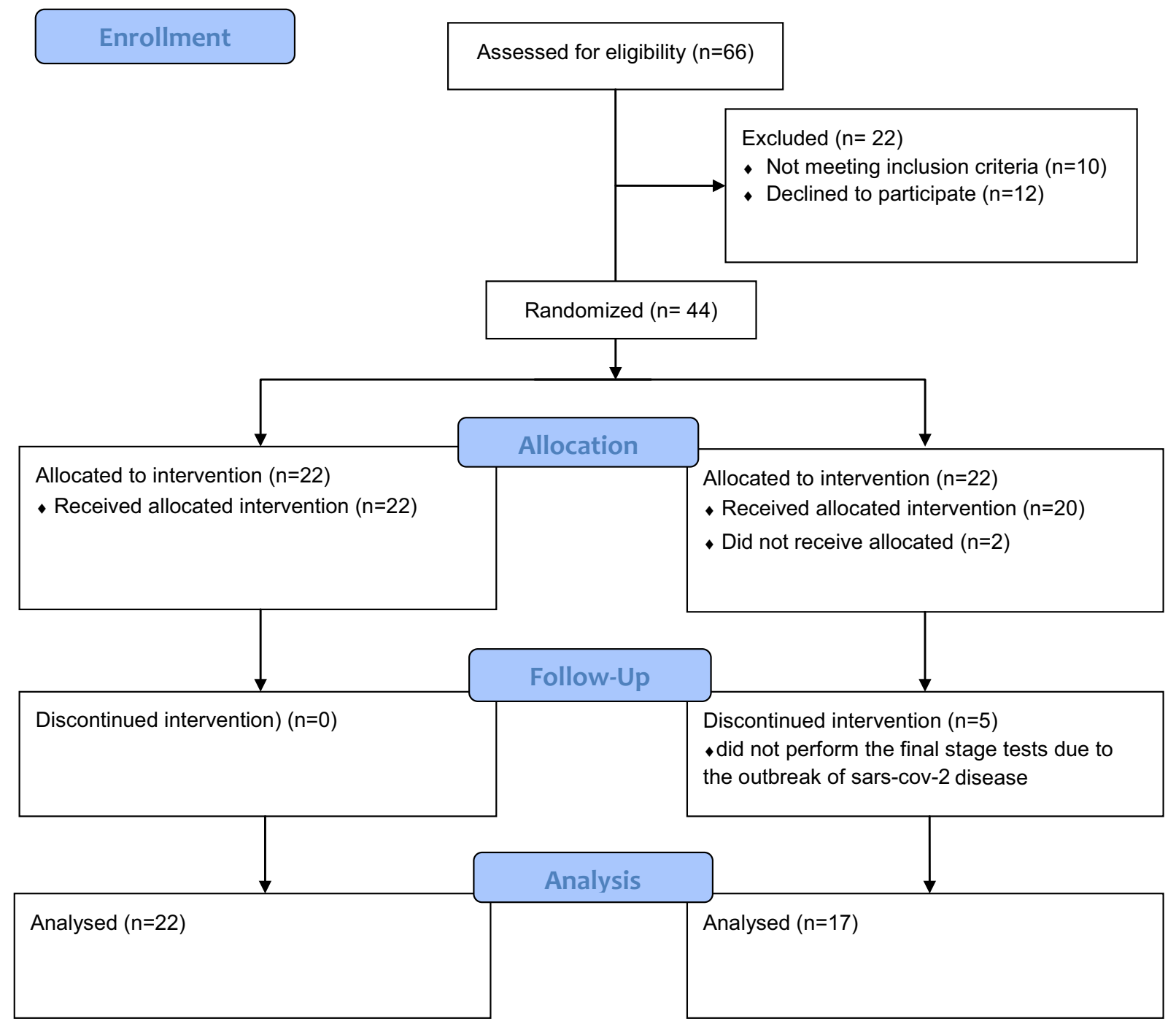

Fig. 1 CONSORT flow diagram of screening, randomization, and treatment of participants enrolled the study

significant difference in the use of these drugs between the two groups (Table 1). All patients receiving verapamil and placebo also received metformin and sitagliptin. Two people withdrew early in the study; five others did not participate in the end-of-study tests due to the outbreak of the SARS-CoV-2 disease (Fig. 1).
Table 1 also presents the demographic and general characteristics of the 42 patients who completed the study. Mean age, proportion of men and women in each group, mean blood pressure (not shown), body weight, and body mass index were similar between the two groups. The two groups also presented no statistically significant differences regarding use of 
Table 2 Laboratory test results at baseline of participants who completed the study

\begin{tabular}{lccc}
\hline Variables & Verapamil group & Placebo group & $\boldsymbol{p}$ value \\
\hline HbAlc $(\%)$ & $7.5 \pm 1$ & $8.3 \pm 1.9$ & 0.141 \\
FBS $(\mathrm{mg} / \mathrm{dl})$ & $131.7 \pm 39$ & $125.3 \pm 36$ & 0.586 \\
Triglycerides $(\mathrm{mg} / \mathrm{dl})$ & $153.9 \pm 84.5$ & $143.7 \pm 49.5$ & 0.640 \\
Total cholesterol (mg/dl) & $123.5 \pm 34.8$ & $130.6 \pm 32.4$ & 0.505 \\
LDL-cholesterol (mg/dl) & $54.2 \pm 24.6$ & $62.1 \pm 26$ & 0.320 \\
HDL-cholesterol (mg/dl) & $38.4 \pm 6.6$ & $39.3 \pm 6.8$ & 0.669 \\
\hline
\end{tabular}

Data are shown as the mean \pm SD

FBS Fasting blood sugar (glucose), $H b A 1 c$ hemoglobin A1c, $H D L$ high-density lipoprotein, $L D L$ low-density lipoprotein

Table 3 Effect of verapamil on HbAlc, FBS, and lipid profile in patients with T2DM at end of intervention (90 days)

\begin{tabular}{lccc}
\hline Variables & Verapamil & Placebo & $\boldsymbol{p}$ value \\
\hline HbAlc $(\%)$ & $7.1 \pm 1$ & $8.2 \pm 1.5$ & $0.012^{*}$ \\
FBS $(\mathrm{mg} / \mathrm{dl})$ & $126.5 \pm 34.1$ & $134.9 \pm 43.4$ & 0.448 \\
Triglycerides $(\mathrm{mg} / \mathrm{dl})$ & $149.7 \pm 77.3$ & $161.6 \pm 61.4$ & 0.587 \\
Total cholesterol $(\mathrm{mg} / \mathrm{dl})$ & $126.5 \pm 29.7$ & $136.2 \pm 33.2$ & 0.327 \\
LDL-cholesterol $(\mathrm{mg} / \mathrm{dl})$ & $58.3 \pm 22.6$ & $63.7 \pm 22.8$ & 0.448 \\
HDL-cholesterol $(\mathrm{mg} / \mathrm{dl})$ & $40.5 \pm 7.9$ & $40 \pm 8.8$ & 0.850 \\
\hline
\end{tabular}

Comparison of change between verapamil and placebo values 90 days after initiation of intervention. Data are shown as the mean $\pm S T$

*Significant difference at $p<0.05$

oral antihyperglycemic agents and antihyperlipidemic drugs at the start of the study, and there were no significant between-group differences in baseline HbA1c, FBS, or lipid profiles (Table 2).

\section{Effect of Verapamil on HbA1c and FBS}

Hemoglobin A1C and FBS levels were measured at baseline and at the end of the study (Table 3). At the end of the study, the mean HbA1c was significantly lower in the verapamil group than in the placebo group ( $p=0.012$; Table 3). Although FBS was also lower in the verapamil group than in the placebo group, this difference was not statistically significant (Table 3 ).
There was no significant difference between FBS at end of the intervention and that at baseline within either treatment group (Table 4). FBS decreased by $>5$ units on average in the verapamil group and increased by $>7$ units in the placebo group, but this difference was not significant. HbA1c significantly increased in the verapamil group at the end of the intervention compared to baseline $(p=$ 0.047; Table 4). The decrease in mean hemoglobin A1C in the verapamil group was about $0.5 \%$.

\section{Effect of Verapamil on Lipid Profile}

Comparisons of lipid profiles (including TG, cholesterol, LDL, and HDL) at the end of the 
Table 4 Comparison of change in HbAlc, FBS and lipid profile in patients with T2DM after 90 days versus baseline in the verapamil and placebo group

\begin{tabular}{|c|c|c|c|c|c|c|}
\hline \multirow[t]{2}{*}{ Variables } & \multicolumn{2}{|c|}{ Verapamil group } & \multicolumn{2}{|c|}{ Placebo group } & \multicolumn{2}{|l|}{$p$ value $^{a}$} \\
\hline & Before & After & Before & After & $\begin{array}{l}\text { Verapamil } \\
\text { group }\end{array}$ & $\begin{array}{l}\text { Placebod } \\
\text { group }\end{array}$ \\
\hline HbAlc (\%) & $7.5 \pm 1$ & $7.1 \pm 1$ & $8.3 \pm 1.9$ & $8.2 \pm 1.5$ & $0.047^{*}$ & 0.855 \\
\hline FBS $(\mathrm{mg} / \mathrm{dl})$ & $131.7 \pm 39$ & $126.5 \pm 34.1$ & $125.3 \pm 36$ & $134.9 \pm 43.4$ & 0.493 & 0.241 \\
\hline Triglycerides (mg/dl) & $153.9 \pm 84.5$ & $149.7 \pm 77.3$ & $143.7 \pm 49.5$ & $161.6 \pm 61.4$ & 0.844 & 0.105 \\
\hline $\begin{array}{l}\text { Total cholesterol (mg/ } \\
\text { dl) }\end{array}$ & $123.5 \pm 34.8$ & $126.5 \pm 29.7$ & $130.6 \pm 32.4$ & $136.2 \pm 33.2$ & 0.686 & 0.388 \\
\hline $\begin{array}{l}\text { LDL-cholesterol (mg/ } \\
\text { dl) }\end{array}$ & $54.2 \pm 24.6$ & $58.3 \pm 22.6$ & $62.1 \pm 26$ & $63.7 \pm 22.8$ & 0.495 & 0.778 \\
\hline $\begin{array}{l}\text { HDL-cholesterol (mg/ } \\
\text { dl) }\end{array}$ & $38.4 \pm 6.6$ & $40.5 \pm 7.9$ & $39.3 \pm 6.8$ & $40 \pm 8.8$ & 0.100 & 0.468 \\
\hline
\end{tabular}

Data are shown as mean \pm SD

*Significant difference at $p<0.05$

a Significance is shown for each treatment group regarding the difference between baseline and end of intervention

study revealed no significant differences between the two groups (Table 3). Decreased TG and cholesterol levels were detected in the verapamil group at the end of the study compared to the baseline level, although this decrease was not statistically significant (Table 4). Also, HDL levels slightly increased in the verapamil group at the end of the study compared to the baseline data, but again the difference was not statistically significant (Table 4). In the placebo group, TG, cholesterol, and LDL had increased by the end of the study compared to baseline levels, but the differences were not significant (Table 4); HDL also showed a slight, but nonsignificant increase.

\section{Effect of Verapamil on TXNIP Gene Expression}

Expression of the TXNIP gene throughout the study (measured on days 15, 30, and 90) was lower in the verapamil group than in the placebo group. In the first month of the study (days 15 and 30), TXNIP gene expression was lower in the verapamil group than in the placebo group, but the difference at both time- points was not statistically significant $(p=0.104$ and $p=0.475$, respectively). By the end of the study, TXNIP gene expression had increased in both groups, but the difference was not statistically significant (Table 5). Comparisons of TXNIP gene expression within verapamil group showed that the expression of this gene increased by the end of the study despite an initial decrease during the first month. However, no significant within-group differences were observed between any given measurement and the following one (i.e., baseline vs. day 15 , day 15 vs. day 30, and day 30 vs. day 90).

\section{Effect of Verapamil on GLP1R mRNA}

The amount of GLP1R mRNA in the first month of the intervention was higher in the verapamil group than in the placebo group, but the difference was not significant $(p=0.809$ and $p=$ 0.860 , respectively). At end of the study, GLP1R mRNA levels had decreased in both groups, but the difference was not significant $(p=0.236)$. A comparison of GLP1R mRNA values within each group showed that after the initial increase in the first month, the values had decreased at the 
Table 5 Effect of verapamil on thioredoxin interacting protein gene expression in patients with T2DM after 15, 30, and 90 days

\begin{tabular}{llll}
\hline Variables & Verapamil group & Placebo group & $\boldsymbol{p}$ value \\
\hline TXNIP gene expression at baseline & 1 & 1 & \\
TXNIP gene expression after 15 days & $0.977 \pm 0.88$ & $1.64 \pm 1.29$ & 0.104 \\
TXNIP gene expression after 30 days & $0.960 \pm 0.74$ & $1.204 \pm 1.18$ & 0.475 \\
TXNIP gene expression after 90 days & $1.206 \pm 0.68$ & $1.280 \pm 1.16$ & 0.823 \\
\hline
\end{tabular}

Data are shown as mean \pm SD. All quantities are expressed as fold differences relative to cDNA (complementary DNA) of housekeeping gene (beta-actin; ACTB)

Relative quantification was calculated for the TXNIP gene using the $2^{-\Delta \Delta C t}$ method

TXNIP Thioredoxin interacting protein

end of the study. In the placebo group, there were no significant differences between any given measurement and the following one (day 15 vs. baseline, day 30 vs. day 15, and the end of the study vs. day 30). In the verapamil group, after an initial increase in the first month, a significant decrease was observed at the end of the intervention compared to day 30 ( $p=$ $0.040)$.

\section{DISCUSSION}

In this study, verapamil was well-tolerated in patients who received the drug. Although some mild side effects were observed in a few patients, no significant side effects were reported. Therefore, no discontinuation of treatment or dose reductions were necessary.

Pancreatic beta cells have a weak antioxidant system and are highly sensitive to oxidative stress reactions that occur within the cell [3]. TXNIP reduces the antioxidant capacity of cells and induces oxidative stress and apoptosis in pancreatic beta cells. Verapamil is a non-dihydropyridine calcium channel blocker thas has recently been shown in cell culture medium and in an animal model to improve beta cell survival and glucose homeostasis by reducing TXNIP expression [33].

The benefits of verapamil, in addition to those observed in preclinical studies, include positive effects on patients with T2DM, as observed in several retrospective studies. These studies included an analysis of Taiwan's National Health Insurance Research Database, the INVEST study, and the REGAREDS cohort study [37]. In addition to these studies, a clinical trial in patients with newly diagnosed type 1 diabetes showed that verapamil can improve beta cell mass function and reduce insulin requirements [38].

The present study was the first double-blind prospective clinical trial performed on patients with T2DM. The results showed that adding verapamil to the treatment regimen of these patients could help to control blood sugar levels. This finding was represented as a decrease in HbA1c. In this study, the decrease in mean $\mathrm{HbA1c}$ in patients receiving $120 \mathrm{mg}$ verapamil per day was about $0.5 \%$ after 3 months. In the verapamil group, FBS decreased by an average of $7 \mathrm{mg} / \mathrm{dl}$ (not statistically significant) by the end of the study when compared to the baseline.

The efficacy of verapamil in this study is consistent with the confirmed effects of this drug in preclinical studies on human isolated islet cells and animal models [33]. These earlier studies showed that verapamil reduced oxidative stress in Langerhans beta cells by reducing TXNIP gene expression and improving glucose homeostasis [33]. Based on these results, we expected that TXNIP gene expression would decrease in our patients with T2DM who received verapamil. As expected, TXNIP gene expression did decrease in the patient group that received verapamil in the first month of 


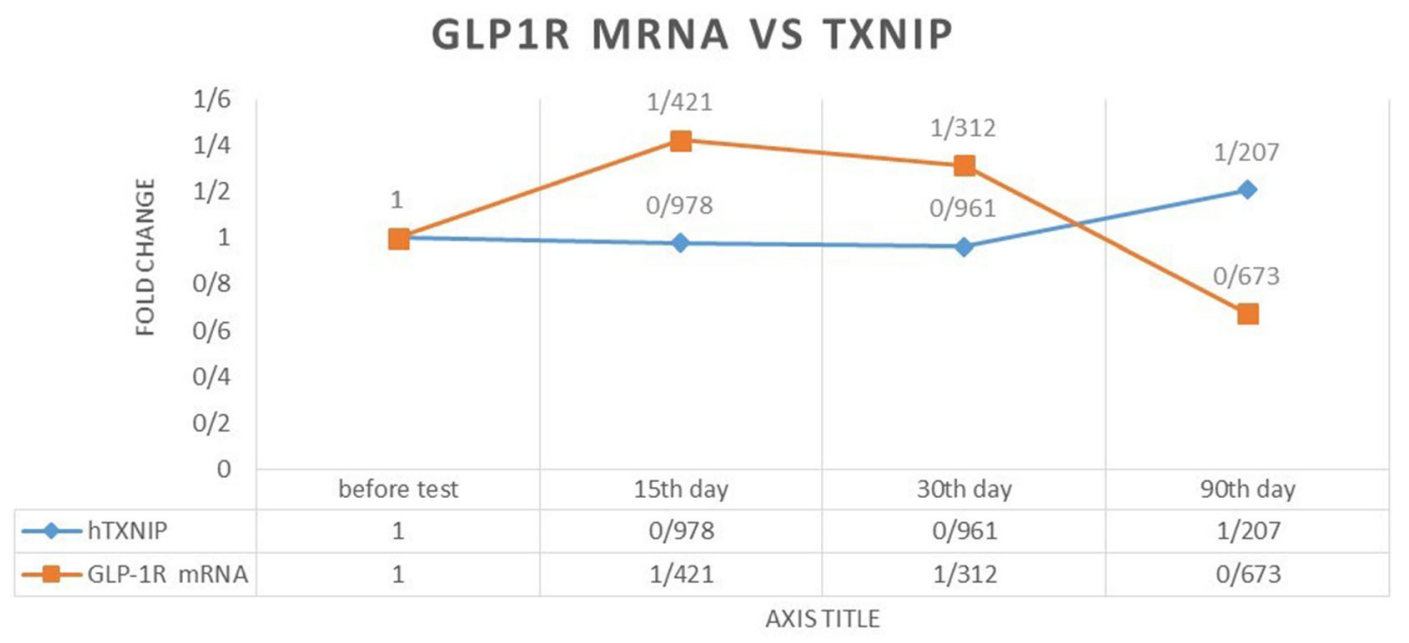

Fig. 2 Comparison of thioredoxin interacting protein (TXNIP) gene expression and glucagon like peptide-1 receptor $(G L P-1 R)$ mRNA in patients with T2DM randomized to the verapamil group

Table 6 Effect of verapamil on glucagon-like peptide-1 receptor mRNA in patients with T2DM after 15, 30 and 90 days

\begin{tabular}{llll}
\hline Variables & Verapamil & Placebo & $\boldsymbol{p}$ value \\
\hline GLP1R mRNA at baseline & 1 & 1 & \\
GLP1R mRNA after 15 days & $1.420 \pm 1.52$ & $1.284 \pm 1.66$ & 0.809 \\
GLP1R mRNA after 30 days & $1.311 \pm 1.21$ & $1.245 \pm 0.86$ & 0.860 \\
GLP1R mRNA after 90 days & $0.673 \pm 0.70$ & $0.992 \pm 0.813$ & 0.236 \\
\hline
\end{tabular}

Data are shown as mean \pm SD. All quantities are expressed as fold differences relative to cDNA of housekeeping gene (ACTB). Relative quantification was calculated for GLP1R mRNA using the $2^{-\Delta \Delta C T}$ method GLPIR Glucagon like peptide-1 receptor

intervention. Within the verapamil group, TXNIP expression decreased, although not statistically significant, after 15 and 30 days (Table 5).

Also, compared to the placebo group, the verapamil group experienced a greater GLP1R mRNA increase following the decrease in TXNIP gene expression after 15 and 30 days. However, these differences were not significant (Table 6). The inverse relationship between TXNIP gene expression and GLP1R mRNA levels in our T2DM patients (see Fig. 2) is an important issue identified in this study.

At the end of the study, the effects of both genetic factors were the opposite of the predicted effects. The increase in TXNIP gene expression and decrease in GLP1R mRNA at the end of the study is likely due to the resistance of the TXNIP gene to verapamil and its switching behavior. Higher doses of verapamil should be tested in future studies in an attempt to prevent this switching, which may lead to a difference in gene expression between the verapamil and placebo groups.

The decreases in TXNIP gene expression in preclinical studies were dose-dependent. Therefore, it can be expected that a two- to three-fold increase in the dose of verapamil would further decrease TXNIP gene expression and, consequently, increase GLP1R mRNA. Verapamil doses that are two- to threefold higher than those used in the present study are 
still within the therapeutic range. A dose of $120 \mathrm{mg}$ per day was used in this study because this dose reflects the standard dose prescribed by the country's physicians (as extracted from the Rational Use of Drug Committee of Khuzestan, Iran). Also, the Ethics Committee of Ahvaz Jundishapur University of Medical Sciences deemed higher doses unacceptable since this study represents the first administration of verapamil in patients with T2DM.

In addition to increasing the dose, we recommend that a sustained release (SR) formulation of verapamil be used in order to better evaluate its effect on TXNIP gene expression. A SR formulation would reduce fluctuations in verapamil plasma concentration and, consequently, effectively control increases in TXNIP gene expression after the initial decrease. This is an area for future investigations. However, verapamil's possible mechanism of action in patients with T2DM is as yet not well understood, and other possible positive effects of the drug (e.g., improved insulin sensitivity and gluconeogenesis inhibition) cannot be ignored.

The most notable limitation of the present work is the small number of patients [38]. Therefore, the effectiveness of verapamil should be confirmed in future studies with more patients and a longer study period.

Since a decrease in TXNIP can be associated with an increase in GLP1Rs [28], using verapamil in combination with other drugs that act through this receptor (such as GLP1 agonists and DPP-4 inhibitors) may yield promising outcomes. This issue should be investigated in future studies. Also, verapamil use might improve blood glucose control and reduce the need for insulin in patients with T2DM who use insulin; thus research on the use of verapamil in this patient group is recommended.

\section{CONCLUSION}

Verapamil can lead to better control of T2DM by reducing TXNIP gene expression and increasing beta cell survival and, possibly, by other mechanisms. Due to the safety and efficacy of verapamil, its suitability for being added to common drug treatments, at least in some
T2DM patients, can be confirmed by conducting additional studies.

\section{ACKNOWLEDGEMENTS}

The authors would like to thank all patients who participated in this study.

Compliance with Ethics Guidelines. The trial protocol was approved by the Ahvaz Jundishapur University of Medical Sciences and complied with all ethical regulations (IR.AJUMS.REC.1394.284). All patients signed a written informed consent. This study was performed in accordance with the Helsinki Declaration of 1964 and its later amendments.

Funding. This research project has been financially supported by Ahvaz Jundishapur University of Medical Sciences. No funding or sponsorship was received for the publication of this article.

Authorship. All named authors meet the International Committee of Medical Journal Editors (ICMJE) criteria for authorship for this article, take responsibility for the integrity of the work as a whole, and have given their approval for this version to be published.

Author Contributions. AM and AAH convinced and designed the studies. MZ and FR were responsible for patient selection and patient care. MZ, FR, and HG performed the study. FR and KAA collected the data, performed the analysis, and prepared the tables. MZ wrote the manuscript. All authors reviewed and approved the manuscript.

Disclosures. Alireza Malayeri, Mehrnoosh Zakerkish, Farrokh Ramesh, Hamid Galehdari, Ali Asghar Hemmati and Kambiz A.Angali have nothing to disclose.

Data Availability. The datasets generated during and/or analyzed during the current study are available from the corresponding author on reasonable request. 
Open Access. This article is licensed under a Creative Commons Attribution-NonCommercial 4.0 International License, which permits any non-commercial use, sharing, adaptation, distribution and reproduction in any medium or format, as long as you give appropriate credit to the original author(s) and the source, provide a link to the Creative Commons licence, and indicate if changes were made. The images or other third party material in this article are included in the article's Creative Commons licence, unless indicated otherwise in a credit line to the material. If material is not included in the article's Creative Commons licence and your intended use is not permitted by statutory regulation or exceeds the permitted use, you will need to obtain permission directly from the copyright holder. To view a copy of this licence, visit http://creativecommons.org/licenses/by$\mathrm{nc} / 4.0 /$.

\section{REFERENCES}

1. Khardori R, Griffins GT. Type 2 diabetes mellitus: Medscape, Updated: Jul 13, 2021. https:// emedicine.medscape.com/article/117853-overview.

2. Bergenstal R, Kendall D, Franz M, Rubenstein A. Management of type 2 diabetes: a systematic approach to meeting the standards of care. II: Oral agents, insulin, and management of complications. Endocrinology, 4th edn. Philadelphia: WB Saunders Co; 2001.

3. Muoio DM. TXNIP links redox circuitry to glucose control. Cell Metab. 2007;5:412-4.

4. Shalev A. Minireview: thioredoxin-interacting protein: regulation and function in the pancreatic $B$ cell. Mol Endocrinol. 2014;28:1211-20.

5. Holmgren A. Thioredoxin and glutaredoxin systems. J Biol Chem. 1989;264:13963-6.

6. Nishiyama A, Masutani H, Nakamura H, Nishinaka Y, Yodoi J. Redox regulation by thioredoxin and thioredoxin-binding proteins. IUBMB Life. 2001;52: 29-33.

7. Holmgren A. Thioredoxin catalyzes the reduction of insulin disulfides by dithiothreitol and dihydrolipoamide. J Biol Chem. 1979;254:9627-32.
8. Saitoh M, Nishitoh H, Fujii M, et al. Mammalian thioredoxin is a direct inhibitor of apoptosis signalregulating kinase (ASK) 1. EMBO J. 1998;17: 2596-606.

9. Liu Y, Min W. Thioredoxin promotes ASK1 ubiquitination and degradation to inhibit ASK1-mediated apoptosis in a redox activity-independent manner. Circ Res. 2002;90:1259-66.

10. Patwari P, Chutkow WA, Cummings $\mathrm{K}$, et al. Thioredoxin-independent regulation of metabolism by the $\alpha$-arrestin proteins. J Biol Chem. 2009;284:24996-5003.

11. Dunn LL, Buckle AM, Cooke JP, Ng MK. The emerging role of the thioredoxin system in angiogenesis. Arterioscler Thromb Vasc Biol. 2010;30: 2089-98.

12. Junn E, Han SH, Im JY, et al. Vitamin $\mathrm{D}_{3}$ up-regulated protein 1 mediates oxidative stress via suppressing the thioredoxin function. J Immunol. 2000;164:6287-95.

13. Schulze PC, De Keulenaer GW, Yoshioka J, Kassik $\mathrm{KA}$, Lee RT. Vitamin $\mathrm{D}_{3}$-upregulated protein-1 (VDUP-1) regulates redox-dependent vascular smooth muscle cell proliferation through interaction with thioredoxin. Circ Res. 2002;91:689-95.

14. Schulze PC, Yoshioka J, Takahashi T, He Z, King GL, Lee RT. Hyperglycemia promotes oxidative stress through inhibition of thioredoxin function by thioredoxin-interacting protein. J Biol Chem. 2004;279:30369-74.

15. Saxena G, Chen J, Shalev A. Intracellular shuttling and mitochondrial function of thioredoxin-interacting protein. J Biol Chem. 2010;285:3997-4005.

16. Chen KS, DeLuca HF. Isolation and characterization of a novel cDNA from HL-60 cells treated with 1, 25-dihydroxyvitamin D-3. Biochim Biophys Acta. 1994;1219:26-32.

17. Shalev A, Pise-Masison CA, Radonovich M, et al. Oligonucleotide microarray analysis of intact human pancreatic islets: Identification of glucoseresponsive genes and a highly regulated TGF $\beta$ signaling pathway. Endocrinology. 2002;143:3695-8.

18. Parikh H, Carlsson E, Chutkow WA, et al. TXNIP regulates peripheral glucose metabolism in humans. PLoS Med. 2007;4:e158.

19. Chen J, Jing G, Xu G, Shalev A. Thioredoxin-interacting protein stimulates its own expression via a positive feedback loop. Mol Endocrinol. 2014;28: 674-80. 
20. Shaked M, Ketzinel-Gilad M, Ariav Y, Cerasi E, Kaiser N, Leibowitz G. Insulin counteracts glucotoxic effects by suppressing thioredoxin-interacting protein production in INS-1E $\beta$ cells and in Psammomys obesus pancreatic islets. Diabetologia. 2009;52:636-44.

21. $\mathrm{Ng} \mathrm{MK}, \mathrm{Wu} \mathrm{J}$, Chang E, et al. A central role for nicotinic cholinergic regulation of growth factorinduced endothelial cell migration. Arterioscler Thromb Vasc Biol. 2007;27:106-12.

22. Forrester MT, Seth D, Hausladen A, et al. Thioredoxin-interacting protein (TXNIP) is a feedback regulator of S-nitrosylation. J Biol Chem. 2009;284: 36160-6.

23. Farrell MR, Rogers LK, Liu Y, Welty SE, Tipple TE. Thioredoxin-interacting protein inhibits hypoxiainducible factor transcriptional activity. Free Radic Biol Med. 2010;49:1361-7.

24. Spindel ON, World C, Berk BC. Thioredoxin interacting protein: redox dependent and independent regulatory mechanisms. Antioxid Redox Signal. 2012;16:587-96.

25. Xu G, Chen J, Jing G, Shalev A. Thioredoxin-interacting protein regulates insulin transcription through microRNA-204. Nat Med. 2013;19:1141-6.

26. Minn AH, Pise-Masison CA, Radonovich M, et al. Gene expression profiling in INS-1 cells overexpressing thioredoxin-interacting protein. Biochem Biophys Res Commun. 2005;336:770-8.

27. Wang Y, De Keulenaer GW, Lee RT. Vitamin $D_{3}$-upregulated protein-1 is a stress-responsive gene that regulates cardiomyocyte viability through interaction with thioredoxin. J Biol Chem. 2002;277: 26496-500.

28. Jo S, Chen J, Xu G, Grayson TB, Thielen LA, Shalev A. miR-204 controls glucagon-like peptide 1 receptor expression and agonist function. Diabetes. 2018;67(2):256-64.

29. Echizen H, Eichelbaum M. Clinical pharmacokinetics of verapamil, nifedipine and diltiazem. Clin
Pharmacokinet. 1986;11(6):425-49. https://doi.org/ 10.2165/00003088-198611060-00002.

30. FDA Approved Drug Products: Verelan PM (verapamil hydrochloride). Accessdata.fda.gov

31. Verapamil FDA Label. https://www.accessdata.fda. gov

32. FDA Approved Drug Products: CALAN SR (verapamil hydrochloride). Accessdata.fda.gov

33. Xu G, Chen J, Jing G, Shalev A. Preventing beta-cell loss and diabetes with calcium channel blockers. Diabetes. 2012;61:848-56.

34. Yin T, Kuo SC, Chang YY, Chen YT, Wang KK. Verapamil use is associated with reduction of newly diagnosed diabetes mellitus. J Clin Endocrinol Metab. 2017;102:2604-10.

35. Cooper-Dehoff R, Cohen JD, Bakris GL, et al. Predictors of development of diabetes mellitus in patients with coronary artery disease taking antihypertensive medications (findings from the International Verapamil SR-Trandolapril Study [INVEST]). Am J Cardiol. 2006;98:890-4.

36. Cooper-DeHoff RM, Aranda JM Jr, Gaxiolaet E, et al. Blood pressure control and cardiovascular outcomes in high-risk Hispanic patients: Findings from the International Verapamil SR/Trandolapril Study (INVEST). Am Heart J. 2006;151:1072-9.

37. Khodneva Y, Shalev A, Frank SJ, Carson AP, Safford MM. Calcium channel blocker use is associated with lower fasting serum glucose among adults with diabetes from the REGARDS study. Diabetes Res Clin Pract. 2016;115:115-21.

38. Ovalle F, Grimes T, Xu G, et al. Verapamil and beta cell function in adults with recent-onset type 1 diabetes. Nat Med. 2018;24(8):1108-12.

39. Livak KJ, Schmittgen TD. Analysis of relative gene expression data using real-time quantitative PCR and the 2(-Delta Delta C(T)) Method. Methods. 2001;25(4):402-8. https://doi.org/10.1006/meth. 2001.1262 . 